\title{
Multi-analytical evaluation of serum levels of cytokines and adhesion molecules in patients treated for acute myeloid leukemia using biochip array technology
}

\author{
Jan M. Horacek ${ }^{a, b}$, Martina Vasatovac, Tomas Kupsa ${ }^{a, b}$, Ladislav Jebavy ${ }^{a, b}$, Pavel Zak ${ }^{b}$
}

\begin{abstract}
Aims. Evaluation of serum levels of 17 cytokines and 5 adhesion molecules in patients treated for acute myeloid leukemia (AML) using biochip array technology. This approach allows multi-analytical determination from a single sample. Methods. A total of $15 \mathrm{AML}$ patients were studied. Blood samples were taken at the diagnosis (active leukemia) and at circa 6 months after completion of last chemotherapy (durable complete remission in all patients).

Results. Comparing cytokine and adhesion molecule levels in active leukemia and in durable complete remission, we found significant increase $(P<0.01)$ in serum interleukin-7 (IL-7), epidermal growth factor $(E G F)$, vascular endothelial growth factor (VEGF), and significant decrease $(P<0.01)$ in serum E-selectin.

Discussion. Our results indicate that serum levels of specific cytokines and adhesion molecules (IL-7, EGF, VEGF, E-selectin) are significantly altered in patients treated for AML, reflecting activity of the disease. Further investigation is needed to establish if the changes observed in the levels of these molecules could be used as a prognostic indicator of AML.
\end{abstract}

Key words: cytokines, adhesion molecules, biochip array, acute myeloid leukemia

Received: March 26, 2013; Accepted with revision: September 17, 2013; Available online: September 27, 2013 http://dx.doi.org/10.5507/bp.2013.073

aDepartment of Internal Medicine, Faculty of Military Health Sciences, University of Defence, Hradec Kralove, Czech Republic ${ }^{b} 4^{\text {th }}$ Department of Internal Medicine - Hematology, Faculty of Medicine in Hradec Kralove, Charles University in Prague and University Hospital Hradec Kralove, Hradec Kralove

Institute of Clinical Biochemistry and Diagnostics, University Hospital Hradec Kralove, Hradec Kralove

Corresponding author: Jan M. Horacek, e-mail: horacek@pmfhk.cz

\section{INTRODUCTION}

Cytokines and adhesion molecules have been studied in many pathological states including hematological malignancies ${ }^{1,2}$ and acute myeloid leukemia (AML) (ref., ${ }^{3,4}$ ). Alterations in this interacting functional network may have direct effect on the malignant cells or have indirect effect on leukemogenesis through altered functions of bone marrow stromal elements ${ }^{5,6}$. The knowledge gained from multi-analytical determination of cytokines and adhesion molecules could allow better diagnosis and management of hematological malignancies, since cytokines or their receptors may also represent a target for specific anticancer therapy at the molecular level. Recently, some studies reported the possible diagnostic and prognostic use of cytokine levels in newly diagnosed AML and myelodysplastic syndromes ${ }^{7-9}$.

The aim of our pilot study was to evaluate serum levels of cytokines and adhesion molecules in patients treated for AML using the innovative biochip array technology. This generates a patient profile, which is relevant when investigating interacting functional networks.

\section{PATIENTS AND METHODS}

\section{Patients}

A total of 15 AML patients (mean age $48.7 \pm 12.1$ years, median 51,8 males and 7 females) treated with cyclic chemotherapy (regimen " $3+7$ ", " $2+5$ ", HiDAC) alone or in combination with high-dose chemotherapy (myeloablative preparative regimen $\mathrm{Bu} / \mathrm{Cy} 2$ or $\mathrm{Cy} / \mathrm{TBI}$ ) followed by autologous hematopoietic stem cell transplantation (HSCT) were studied. To have a homogeneous group, patients undergoing allogeneic HSCT were excluded from the analysis. According to FAB classification, 2 patients had AML M1, 11 patients AML M2 and 2 patients AML M4. According to cytogenetics, 12 patients were intermediate risk (normal karyotype) and 3 patients better risk (core-binding factor abnormalities). No patient had hyperleukocytosis above $50.000 / \mu \mathrm{L}$ at the diagnosis of AML. All patients were in durable first complete remission (CR) at circa 6 months after completion of last chemotherapy. The study was approved by the local Ethics Committee and all patients gave a written consent.

\section{Multi-analytical evaluation}

We evaluated circulating levels of the following 17 cytokines and 5 adhesion molecules: interleukins (IL-1 alpha, IL-1 beta, IL-2, IL-3, IL-4, IL-6, IL-7, IL-8, IL-10, IL-12p70, IL-13, IL-23), vascular endothelial growth fac- 
tor (VEGF), tumor necrosis factor-alpha (TNF-alpha), interferon-gamma (IFN-gamma), epidermal growth factor (EGF), monocyte chemotactic protein-1 (MCP-1), E-selectin, L-selectin, P-selectin, intercellular adhesion molecule-1 (ICAM-1), vascular cell adhesion molecule-1 (VCAM-1). All analytes were measured by biochip array technology using chemiluminescent sandwich immunoassays applied to the Evidence Investigator analyzer (Randox Laboratories Ltd., Crumlin, UK). We analyzed serum samples at the diagnosis of AML (active leukemia) and in durable first $\mathrm{CR}$ at circa 6 months after completion of last chemotherapy.

Statistical analysis was performed with the "Statistica" program. Paired t-tests were used. The values were expressed as mean \pm SD. Probability values $(P)<0.01$ were considered statistically significant.

\section{RESULTS}

Comparing serum cytokine and adhesion molecule levels in active leukemia and in durable $\mathrm{CR}$, we found significant increase in serum IL-7 (5.34 $\pm 4.32 \mathrm{ng} / \mathrm{L}$ vs. $19.62 \pm 12.05 \mathrm{ng} / \mathrm{L} ; P<0.001), \mathrm{EGF}(16.48 \pm 33.50 \mathrm{ng} / \mathrm{L}$ vs. $64.42 \pm 35.33 \mathrm{ng} / \mathrm{L} ; P<0.001)$ and VEGF $(63.93 \pm$ $67.85 \mathrm{ng} / \mathrm{L}$ vs. $114.39 \pm 54.90 \mathrm{ng} / \mathrm{L} ; P<0.01)$. On the other hand, we found significant decrease in serum E-selectin (30.19 $\pm 20.46 \mathrm{mcg} / \mathrm{L}$ vs. $12.99 \pm 8.00 \mathrm{mcg} / \mathrm{L} ; P<0.01)$. No significant differences were found in the levels of other evaluated cytokines and adhesion molecules.

\section{DISCUSSION}

Altered levels of cytokines and adhesion molecules have been found in many pathological states and have been linked to many diseases such as autoimmune diseases, allergies, cardiovascular diseases and cancer ${ }^{10-15}$. The cytokine system constitutes an interacting functional network where the contribution from single cytokines is modulated by the levels of other cytokines. It may therefore be more relevant to look at the total serum profile of cytokines and adhesion molecules.

Biochip array technology enables simultaneous detection of multiple cytokines and adhesion molecules in a single sample and provides valuable information relating to each tested analyte and possible associations between analytes in each sample ${ }^{16,17}$. We previously tested single cytokines and adhesion molecules in leukemia patients. To our knowledge, this is the first published study using the innovative biochip array technology to determine circulating levels of cytokines and adhesion molecules in AML patients.

Our results indicate that serum levels of specific cytokines and adhesion molecules (IL-7, EGF, VEGF, E-selectin) are significantly altered in patients treated for AML, reflecting activity of the disease or changes caused by preceding oncology treatment. Our results are limited by the number of patients included in the study. Whether these alterations in circulating cytokines and adhesion molecules could serve as a prognostic indicator for AML is not clear. Further studies in a larger number of patients and comparing cytokine and adhesion molecule levels with established prognostic markers (cytogenetics, molecular genetics) will be needed to define the potential role of these and additional markers in the risk stratification of AML patients.

\section{ABBREVIATIONS}

AML, Acute myeloid leukemia; CR, Complete remission; EGF, Epidermal growth factor; HSCT, Hematopoietic stem cell transplantation; ICAM-1, Intercellular adhesion molecule-1; IFN-gamma, Interferon-gamma; IL, Interleukin; MCP-1, Monocyte chemotactic protein-1; TNF-alpha, Tumor necrosis factor-alpha; VCAM-1, Vascular cell adhesion molecule-1; VEGF, Vascular endothelial growth factor.

\section{ACKNOWLEDGEMENTS}

The work was supported by a long-term organization development plan 1011 (Faculty of Military Health Sciences, Hradec Kralove) and by a specific research project "Analysis of defined prognostic factors in acute myeloid leukemia" (Faculty of Military Health Sciences, Hradec Kralove).

\section{CONFLICT OF INTEREST STATEMENT}

Author's conflict of interest disclosure: None declared.

\section{REFERENCES}

1. Bruserud $\varnothing$, Kittang AO. The chemokine system in experimental and clinical hematology. Curr Top Microbiol Immunol 2010;341:3-12.

2. Deeg HJ. Cytokines in graft-versus-host disease and the graft-versusleukemia reaction. Int J Hematol 2001;74(1):26-32.

3. Löwenberg B, Touw IP. Hematopoietic growth factors and their receptors in acute leukemia. Blood 1993;81(2):281-92.

4. Kupsa T, Horacek JM, Jebavy L. The role of cytokines in acute myeloid leukemia: a systematic review. Biomed Pap Med Fac Univ Palacky Olomouc Czech Repub 2012;156(4):291-301.

5. Konopleva MY, Jordan CT. Leukemia stem cells and microenvironment: biology and therapeutic targeting. Clin Oncol 2011;29(5):5919.

6. Reikvam H, Hatfield KJ, Fredly H, Nepstad I, Mosevoll KA, Bruserud $\varnothing$. The angioregulatory cytokine network in human acute myeloid leukemia - from leukemogenesis via remission induction to stem cell transplantation. Eur Cytokine Netw 2012;23(4):140-53.

7. Tsimberidou AM, Estey E, Wen S, Pierce S, Kantarjian H, Albitar M, Kurzrock R. The prognostic significance of cytokine levels in newly diagnosed acute myeloid leukemia and high-risk myelodysplastic syndromes. Cancer 2008;113(7):1605-13.

8. Kornblau SM, McCue D, Singh N, Chen W, Estrov Z, Coombes KR. Recurrent expression signatures of cytokines and chemokines are present and are independently prognostic in acute myelogenous leukemia and myelodysplasia. Blood 2010;116(20):4251-61.

9. Fung FY, Li M, Breunis $H$, Timilshina N, Minden MD, Alibhai SM Correlation between cytokine levels and changes in fatigue and quality of life in patients with acute myeloid leukemia. Leuk Res 2013;37(3):274-9. 
10. Berrahmoune $H$, Lamont J, Fitzgerald P, Visvikis-Siest S. Interindividual variation of inflammatory markers of cardiovascular risks and diseases. Clin Chem Lab Med 2005;43(7):671-84.

11. Karasek D, Vaverkova $H$, Halenka M, Budikova $M$, Novotny D. Soluble cell adhesion molecules s-VCAM-1 and s-ICAM-1 in subjects with familial combined hyperlipidemia. Biomed Pap Med Fac Univ Palacky Olomouc Czech Repub 2005;149(1):101-8.

12. Kavsak PA, Lee A, Hirte H, Young E, Gauldie J. Cytokine elevations in acute coronary syndrome and ovarian cancer: a mechanism for the up-regulation of the acute phase proteins in these different disease etiologies. Clin Biochem 2008;41(7-8):607-10.

13. Coussens LM, Werb Z. Inflammation and cancer. Nature 2002;420(6917):860-7.
14. Dranoff G. Cytokines in cancer pathogenesis and cancer therapy. Nat Rev Cancer 2004;4(1):11-22.

15. Peric A, Vojvodic D, Baletic N, Peric A, Miljanovic O. Influence of allergy on the immunomodulatory and clinical effects of long-term low-dose macrolide treatment of nasal polyposis. Biomed Pap Med Fac Univ Palacky Olomouc Czech Repub 2010;154(4):327-33.

16. McAleer D, McPhillips FM, FitzGerald SP, McConnell RI, Rodriguez ML. Application of Evidence Investigator for the simultaneous measurement of soluble adhesion molecules: L-, P-, E-selectins, VCAM-1 and ICAM-1 in a biochip platform. J Immunoassay Immunochem 2006;27(4):363-78.

17. Fitzgerald SP, McConnell RI, Huxley A. Simultaneous analysis of circulating human cytokines using a high-sensitivity cytokine biochip array. J Proteome Res 2008;7(1):450-5. 